\title{
A ISENÇÃO DO IMPOSTO DE RENDA SOBRE A DISTRIBUIÇÃO DE LUCROS E DIVIDENDOS À LUZ DO PRINCÍPIO CONSTITUCIONAL DA ISONOMIA
}

\section{THE EXEMPTION FROM INCOME TAX ON THE DISTRIBUTION OF PROFITS AND DIVIDENDS IN THE LIGHT OF THE CONSTITUTIONAL PRINCIPLE OF EQUALITY}

Recebido: 06.06.2017

Aprovado: 18.07.2017

\author{
Danilo Miranda Vieira* \\ Luciana Grassano de Gouvêa Melo**
}

RESUMO: O presente estudo tem como objeto de análise a isenção do imposto de renda sobre a distribuição de lucros e dividendos e sua compatibilidade com a Constituição Federal, especialmente com o princípio da isonomia. Analisou-se, ainda, se a referida norma possui alguma justificação com base em outra finalidade constitucional, à luz da teoria dos princípios e da proporcionalidade. Foi examinado o perfil da tributação e da desigualdade de renda no Brasil, bem como a alegada eficácia da isenção para promover a finalidade extrafiscal pretendida. Ao final, concluiu-se pela inconstitucionalidade da isenção, em face da desproporcional restrição à igualdade que ela representa.

Palavras-chave: Imposto de renda. Isenção. Lucros e dividendos. Princípio da isonomia.

ABSTRACT: The object of analysis in this study is the exemption from income tax on the distribution of profits and dividends and its compatibility with the Federal Constitution, specially the principle of equality. It was also annalyzed if the exemption has any justification based on another constitutional goal, in accordance with the principle of proportionality. It was examined the profile of taxation and income inequality in Brazil, and also the alleged efficiency of the exemption to promote the intended constitutional goal. Finally, the conclusion points to the unconstitutionality of the exemption, due to the disproportional restraint to equality that it represents.

Keywords: Income tax. Exemption. Profits and dividends. Principle of equality.

\section{INTRODUÇÃO}

O art. 10 da Lei no 9.249/95 instituiu a isenção, relativamente ao imposto de renda, dos rendimentos auferidos a título de distribuição de lucros e dividendos. O objetivo do presente estudo é fazer uma análise acerca da compatibilidade da referida isenção com o

\footnotetext{
* É mestrando em Direito (PPGD/UFPE) e Procurador do Município do Recife. E-mail: < dmv_pe@hotmail.com >.

** É doutora em Direito pela UFPE, com estágio pós-doutoral na Universidade de Bolonha, na Itália. Professora associada dos programas de graduação, mestrado e doutorado em Direito da UFPE. Ex-diretora da Faculdade de Direito do Recife/UFPE (2007 a 2015) e Procuradora do Estado de Pernambuco. E-mail: < luggmelo@gmail.com >.
} 
sistema constitucional em vigor, especialmente com o princípio da isonomia, levandose em conta que o imposto de renda deve ser informado pela capacidade contributiva e pela progressividade, conforme determinações constitucionais expressas. Para tanto, recorre-se, em síntese, ao tratamento constitucional da matéria, a posicionamentos de autores da área jurídica sobre o tema e a estudos de economistas sobre o perfil da tributação e da desigualdade no Brasil e no mundo, analisando-se, ao final, se o alcance da finalidade extrafiscal pretendida pelo legislador se justifica em face do postulado da proporcionalidade.

Inicialmente, o princípio da igualdadeé analisado em suas linhas gerais, partindose de sua previsão no sistema constitucional brasileiro. À luz do texto constitucional, é exposta uma breve exposição de seu tratamento por alguns autores que se debruçaram sobre o tema na literatura jurídica.

Em seguida, faz-se uma análise mais específica sobre a concretização do princípio da igualdade no âmbito do direito tributário. Mais uma vez, parte-se do texto constitucional, com ênfase especial na capacidade contributiva e na progressividade, expressamente aplicáveis ao imposto sobre a renda. Também aqui se faz o cotejo com análises doutrinárias sobre o tema no âmbito da tributação.

Posteriormente, é analisada a aparente incompatibilidade da isenção em exame com o princípio da isonomia, informado pelos critérios da capacidade contributiva e da progressividade. Para tanto, busca-se identificar quem são os contribuintes efetivamente beneficiados pela medida, conforme seu nível de renda. Para tanto, foi necessário recorrer a recentes estudos produzidos por autores da área da Economia, que analisam a estrutura efetiva da tributação no Brasil, permitindo-se chegar a conclusões mais fundamentadas sobre o nível real de maior ou menor concretização dos princípios e valores declarados na Constituição.

Nos dois últimos tópicos antes da conclusão, procede-se à análise se a isenção se justifica à luz da finalidade extrafiscal pretendida pelo legislador, com base em um juízo de proporcionalidade. Para tanto, recorre-se mais uma vez a análises de economistas sobre os efeitos de medidas dessa natureza sobre o desenvolvimento e os níveis de desigualdade, a fim de conferir subsídios para a conclusão acerca da compatibilidade ou não da medida com a finalidade declarada de estímulo à economia produtiva. Tais análises econômicas são adotados apenas como elementos complementares ao estudo, sem perder de vista que a abordagem ora adotada é de natureza essencialmente jurídica, não havendo qualquer pretensão de se chegar a conclusões sobre aspectos econômicos da tributação no Brasil.

Após a apresentação desses estudos, fazem-se breves considerações sobre a teoria dos princípios e o postulado ou máxima da proporcionalidade em suas três vertentes (adequação, necessidade e proporcionalidade em sentido estrito), como metanorma destinada a resolver eventuais conflitos entre princípios contrapostos. Também são feitas referências às críticas realizadas a eventuais abusos na ponderação de princípios, considerando-se especialmente os riscos de excessiva ingerência do Poder Judiciário no espaço legítimo de liberdade do legislador. Sem perder de vista as críticas acima 
apontadas, avalia-se, em suma, se a isenção seria efetivamente idônea para alcançar as finalidades pretendidas e se isso compensaria o afastamento pontual do dever de tratamento igualitário dos contribuintes de acordo com sua capacidade econômica, mediante uma ponderação adequada dos princípios jurídicos em jogo.

Finalmente, são apresentadas as conclusões sobre o tema abordado ao longo da exposição.

\section{O PRINCÍPIO DA IGUALDADE}

O princípio da igualdade de todos "perante a lei" se encontra previsto constitucionalmente no art. $5^{\circ}$, caput, da Constituição da República. Em uma acepção excessivamente literal, a igualdade perante a lei pode ser interpretada no sentido restrito de que a lei deve ser aplicada indistintamente a todos que se enquadrem em sua hipótese de incidência. Em se adotando apenas essa concepção reducionista, o legislador estaria livre para impor quaisquer discriminações entre indivíduos e situações. Para se respeitar a isonomia, bastaria assegurar a aplicação das normas discriminatórias em todos os casos legalmente previstos, sem questionamentos sobre a validade em si da discriminação legalmente imposta. O princípio vincularia apenas o aplicador da lei, que não poderia discriminar onde a lei não discriminou.

Contudo, essa aplicação indistinta da norma legal a todos os casos nela previstos configura apenas a chamada igualdade formal. Igualdade essa que se confunde com o próprio princípio da legalidade. Como afirma Kelsen, dizer que o aplicador do Direito só pode levar em conta as diferenciações feitas na própria lei consiste apenas em estabelecer o princípio imanente da legalidade da aplicação das leis, "ou seja, apenas se estatui que as normas devem ser aplicadas de conformidade com as normas”. Assim, uma decisão judicial que estabeleça um tratamento discriminatório não fixado em lei não possuirá qualquer fundamento de anulação e nulidade que seja distinto da mera ilegalidade (KELSEN, 1999, p. 99-100).

Diante da evidente insuficiência da noção exposta de igualdade formal, também se deve fazer referência à igualdade material, a qual decorre de todas as demais garantias previstas no texto constitucional. De modo que as normas jurídicas não podem veicular distinções em desconformidade com a Constituição. Assim, por exemplo, nas licitações públicas não se pode fazer exigências de qualificação técnica que não sejam indispensáveis ao cumprimento das futuras obrigações contratuais, sob pena de ofensa ao art. 37, XXI, da Constituição Federal. O fator de discriminação eleito seria impertinente para a finalidade buscada (regular execução do contrato). Por outro lado, pode-se admitir a estipulação de regras especiais em favor de micro e pequenas empresas nas licitações (arts. 42 a 48 da Lei Complementar no 123/o6), tendo em vista que a Constituição autoriza expressamente o tratamento favorecido a elas dispensado (art. 170, IX). Disso decorre que o dever de isonomia não se destina apenas às autoridades responsáveis pela aplicação da lei, mas também ao legislador. A criação do direito também se sujeita à isonomia, não podendo estabelecer distinções ilegítimas, ofensivas ao ordenamento jurídico vigente. Além disso, nesse sentido material da isonomia, o Estado se converte em promotor ativo da 
igualdade na sociedade, de modo a viabilizar uma igualdade de oportunidades real e não meramente abstrata (VASQUES, 2008, p. 33). A isonomia, portanto, à luz das normas constitucionais, pode não apenas vedar distinções ilegítimas, mas igualmente impor a estipulação de discriminações que visem à consecução dessa igualdade material.

Na lição de Bandeira de Mello, em relação ao conteúdo material do princípio, é insuficiente recorrer apenas à fórmula genérica de que a igualdade consiste em tratar igualmente os iguais e desigualmente os desiguais, a qual deixa em aberto a questão de saber quem são os iguais e quem são os desiguais. Avançando um pouco mais na análise da igualdade material, afirma que qualquer elemento pode ser escolhido pela lei como fator discriminatório, não sendo, em regra, no traço de diferenciação escolhido que se deve avaliar a ocorrência de alguma ofensa à isonomia. As discriminações são compatíveis com o princípio da igualdade quando existe um vínculo de correlação lógica entre o fator de discrímen eleito pela norma e a desigualdade de tratamento em função dele conferida, desde que tal correlação não seja incompatível com interesses protegidos pela Constituição. Assim, a discriminação não pode ser fortuita, devendo existir uma conexão racional entre o tratamento legal diferenciado e a razão que lhe serve de fundamento. Ademais, além da existência do nexo racional apontado, tal vínculo deve ser constitucionalmente pertinente, de modo que as vantagens fundadas em determinada peculiaridade distintiva hão de prestigiar situações compatíveis com interesses albergados na Constituição (BANDEIRA DE MELLO, 2003, p. 10-11, 17, 39, 42).

Ávila define a igualdade como a "relação entre dois ou mais sujeitos, com base em medidas ou critérios de comparação, aferidos por meio de elementos indicativos, que servem de instrumento para a realização de uma determinada finalidade”. A igualdade exige que os sujeitos sejam comparados por critérios que, além de permitidos, sejam relevantes e congruentes para o alcance da finalidade pretendida. A medida de comparação a ser eleita para justificar um tratamento diferenciado deve traduzir uma diferença factual efetivamente existente e que seja pertinente à finalidade que justifica sua utilização. Enfim, a medida, critério ou fator de discriminação deve efetivamente contribuir para a promoção da finalidade buscada pela norma, com base em evidências empíricas. Se não houver um suporte empírico considerável no sentido de que a diferença de tratamento legal efetivamente contribui para a finalidade normativa, a distinção será ofensiva à isonomia. Entre a medida de comparação adotada e a finalidade perseguida deve existir uma relação de causa e efeito (ÁVILA, 2015, p. 45, 48, 54, 57). Também Schoueri aponta que a aplicação do princípio da igualdade pressupõe a eleição de medidas de comparação, algumas eleitas pelo próprio constituinte e outras pelo legislador (2005, p. 274).

Além dessa pertinência efetiva com a finalidade buscada, elemento estrutural do conceito, deve ser agregado um elemento normativo, no sentido de que a medida de comparação que justifica a diferença de tratamento deve ser compatível com a Constituição (ÂVILA, 2015, p. 58). Há casos em que a Constituição veda discriminações com base em determinados fatores ou já define a medida de comparação a ser adotada, excluindo a liberdade do legislador em adotar outro parâmetro. É o que se observa, 
por exemplo, no dispositivo que trata da capacidade contributiva para a graduação dos impostos (art. 145, § 1º, da CF/88). Em razão dessa norma, a medida de comparação eleita para os impostos pessoais é a capacidade econômica dos contribuintes, que deve ser obrigatoriamente adotada pelo legislador Entretanto, mesmo medidas de comparação preliminarmente vedadas pela Constituição podem, eventualmente, ser adotadas pelo legislador em determinadas situações, desde que sejam consentâneas com o alcance de alguma outra finalidade também imposta constitucionalmente, mediante um juízo de proporcionalidade.

Diante do exposto, percebe-se que o princípio da igualdade não pode se reduzir a um sentido estritamente formal, como mera obrigação de aplicação uniforme das normas legais. É forçoso reconhecer que possui, principalmente, um conteúdo material, no sentido de que o legislador não pode instituir tratamentos discriminatórios que não possuam inegável fundamento constitucional. Assim, o conteúdo material do princípio da igualdade deve ser preenchido por todas as normas que compõem o sistema constitucional, as quais podem ser invocadas como finalidades idôneas para justificar determinado tratamento desigual entre os sujeitos, de acordo com critérios que efetivamente promovam o fim buscado. No caso dos tributos, como se verá a seguir, uma das concretizações da igualdade como princípio específico da tributação é a norma atinente à graduação dos impostos de acordo com a capacidade econômica dos contribuintes.

\section{A IGUALDADE NO DIREITO TRIBUTÁRIO}

A igualdade em matéria tributária encontra previsão constitucional específica no art. 150, II, da Constituição Federal. ${ }^{1}$ Esse dispositivo veicula uma regra de igualdade, ao vedar as medidas de comparação nele previstas (ocupação profissional ou função) como critérios de diferenciação válida entre os contribuintes. Tal mandamento constitucional deve ser analisado em conjunto com o princípio da capacidade contributiva, decorrente da isonomia e que está previsto no $\S 1^{\mathrm{o}}$ do art. 145 da Constituição, segundo o qual os impostos devem ser graduados de acordo com a capacidade econômica dos contribuintes. ${ }^{2}$

Já aqui se observa o emprego da igualdade efetivamente como princípio, apontando a norma para um estado ideal de igualdade a ser buscado, no qual os contribuintes sejam tributados de acordo com a capacidade econômica de cada um. Assim, sempre que possível, os impostos devem gravar igualmenteaqueles que possuam a mesma capacidade

1 Art. 150. Sem prejuízo de outras garantias asseguradas ao contribuinte, é vedado à União, aos Estados, ao Distrito Federal e aos Municípios: (...) II - instituir tratamento desigual entre contribuintes que se encontrem em situação equivalente, proibida qualquer distinção em razão de ocupação profissional ou função por eles exercida, independentemente da denominação jurídica dos rendimentos, títulos ou direitos; (...) (BRASIL, 1988) Disponível em: < http://www.planalto.gov.br/ccivil_03/constituicao/constituicaocompilado.htm >.

2 Art. 145. (...) § 1을 Sempre que possível, os impostos terão caráter pessoal e serão graduados segundo a capacidade econômica do contribuinte, facultado à administração tributária, especialmente para conferir efetividade a esses objetivos, identificar, respeitados os direitos individuais e nos termos da lei, o patrimônio, os rendimentos e as atividades econômicas do contribuinte. (BRASIL, 1988). Disponível em: < http://www.planalto.gov.br/ccivil_03/ constituicao/constituicaocompilado.htm $>$. 
contributiva e de forma desigual aqueles que detenham diferentes níveis de riqueza. $\mathrm{O}$ tratamento desigual deve respeitar a capacidade econômica de cada indivíduo/empresa, a fim de realizar a pretendida igualdade material. A rigor, pode-se até sustentar que a capacidade contributiva não configura um princípio autônomo, mas apenas um fator de discrímen, uma medida de comparação já estabelecida constitucionalmente para os impostos pessoais, a fim de concretizar o princípio da isonomia em sua acepção de tratar desigualmente os desiguais.

Para Saldanha Sanches, a capacidade contributiva possui certa "fraqueza conceitual”, por não ser possível defini-la como um critério absolutamente preciso para identificar as boas e más leis fiscais. Paradoxalmente, nisso residiria a força ética da ideia, no sentido de que a distribuição dos encargos deve ter como âncora o conceito ético de capacidade contributiva, diretamente relacionado ao de justiça fiscal. Visa, em última análise, assegurar a "igualdade de sacrifício" na repartição da carga tributária (SALDANHA SANCHES, 2010, p. 30-32). É a igualdade no sacrifício patrimonial imposto aos contribuintes que concretiza a justiça na tributação (VASQUES, 2008, p. 36). Podese acrescentar que essa indeterminação do conceito revela um traço típico de seu caráter principiológico.

De acordo com Vasques, atualmente prevalece o entendimento de que a renda é o melhor indicador da capacidade contributiva. A tributação do rendimento permite apreender a riqueza global do contribuinte, pelo que o imposto sobre a renda deve ser o eixo central do sistema tributário, à luz do princípio da capacidade contributiva (VASQUES, 2008, p. 289; SALDANHA SANCHES, 2010, p. 33). De fato, parece inegável que a capacidade contributiva possui especial importância na tributação da renda, devendo ser tributados de forma mais gravosa aqueles indivíduos que auferem maiores rendimentos.

Os princípios da isonomia e da capacidade contributiva se encontram diretamente relacionados à progressividade. A ideia de progressividade decorre da noção de que a tributação de níveis maiores de renda não deve crescer apenas proporcionalmente, pois quanto maior a renda auferida pelo cidadão, em regra, será menor a essencialidade das despesas a serem custeadas com cada nível adicional de riqueza. Assim, as próprias alíquotas incidentes sobre a base imponível devem ser majoradas conforme o nível de renda. Saldanha Sanches registra que o argumento principal em favor da progressividade é fornecido pela teoria da utilidade marginal decrescente dos rendimentos, no sentido de que as primeiras frações do rendimento proporcionam uma utilidade maior do que as últimas, razão pela qual, se a utilidade de cada fração adicional decresce, o princípio da "igualdade de sacrifício" deve conduzir à estipulação de alíquotas progressivas (SALDANHA SANCHES, 2010, p. 33). Com efeito, se exigir o décimo do rendimento ao homem rico o obriga a prescindir do supérfluo, enquanto ao homem pobre o obriga a prescindir do essencial, a igualdade impõe não apenas a proporcionalidade, mas a progressão do imposto (VASQUES, 2008, p. 294). No Brasil, a progressividade se encontra expressamente prevista para o imposto de renda, no art. 153, § 2º, I, da Constituição da República. 
No caso dos impostos, como visto, a Constituição estabelece, em regra, a capacidade contributiva como medida de comparação a ser adotada, vedando a utilização de qualquer outra para a generalidade dos casos. Efetivamente, trata-se do critério mais adequado para o tratamento dos contribuintes relativamente aos tributos com finalidade essencialmente fiscal, arrecadatória. Atende a uma noção elementar de justiça fiscal, ao exigir de cada cidadão que contribua de acordo com sua capacidade econômica. $\mathrm{Na}$ hipótese excepcional de não se adotar critérios de capacidade contributiva para a incidência de impostos pessoais, como determina a Constituição, deve-se analisar que outra finalidade extrafiscal de estatura constitucional se busca atingir e se o afastamento pontual da capacidade contributiva se encontra em conformidade com o postulado da proporcionalidade. A análise da constitucionalidade da medida dependerá da verificação acerca da razoabilidade e proporcionalidade da discriminação em relação ao fim legislativo buscado (MÉLO, 2008, p. 111). Desde que esse fim, reitere-se, também encontre fundamento no texto constitucional.

\section{A INCOMPATIBILIDADE DA ISENÇÃO SOBRE A DISTRIBUIÇÃO DE LUCROS E DIVIDENDOS COM O PRINCÍPIO DA ISONOMIA}

O art. 10 da Lei no 9.249, de 26 de dezembro de 1995, estabeleceu a isenção de lucros e dividendos em relação ao imposto de renda. ${ }^{3}$ De acordo com Gobetti e Orair, atualmente, no âmbito dos 34 países da OCDE, apenas a Estônia adota um sistema de isenção como o do Brasil. Todos os demais países da OCDE praticam a dupla tributação dos lucros (na pessoa jurídica e na pessoa física). Alguns tributam mais na pessoa jurídica e outros mais na pessoa física, mas, em média, a parte dos lucros absorvida pelo Estado por meio de tributos é bem maior que no Brasil (GOBETTI; ORAIR, 2016, p. 15).

Independentemente de tais comparações, para os fins do presente estudo, o que efetivamente importa é analisar se essa isenção legal é compatível com o princípio da isonomia e com os demaisvalores constitucionais pertinentes. Em primeiro lugar, verificase em tal medida o abandono da capacidade contributiva como critério de graduação do imposto, em discrepância com a regra geral do art. 145, § 1oㅡ. da Constituição.

Nesse passo, é de ver-se que a excessiva concentração de renda e patrimônio segue sendo um sério problema no Brasil e nosso sistema tributário contribui para seu agravamento. Como aponta Salvador, embora tenha havido um significativo aumento da carga tributária desde meados dos anos 90 do século passado, o sistema se concentra em tributos regressivos e indiretos, que penalizam os mais pobres,

\footnotetext{
3 Art. 10. Os lucros ou dividendos calculados com base nos resultados apurados a partir do mês de janeiro de 1996, pagos ou creditados pelas pessoas jurídicas tributadas com base no lucro real, presumido ou arbitrado, não ficarão sujeitos à incidência do imposto de renda na fonte, nem integrarão a base de cálculo do imposto de renda do beneficiário, pessoa física ou jurídica, domiciliado no País ou no exterior. (...) $§ 2^{\circ}$ A não incidência prevista no caput inclui os lucros ou dividendos pagos ou creditados a beneficiários de todas as espécies de ações previstas no art. 15 da Lei no 6.404, de 15 de dezembro de 1976, ainda que a ação seja classificada em conta de passivo ou que a remuneração seja classificada como despesa financeira na escrituração comercial. (BRASIL. 1995). Altera a legislação do imposto de renda das pessoas jurídicas, bem como da contribuição social sobre o lucro líquido, e dá outras providências. Disponível em: < http://www.planalto.gov.br/ccivil_03/leis/L9249.htm >.
} 
[...] uma vez que mais da metade da arrecadação provém de tributos que incidem sobre bens e serviços, havendo baixa tributação sobre a renda e o patrimônio. Nos países socialmente mais desenvolvidos, a tributação sobre o patrimônio e a renda corresponde a cerca de $2 / 3$ da arrecadação dos tributos, conforme dados da OCDE. No Brasil, há uma baixa eficácia redistributiva da política tributária, que não tributa os rendimentos mais elevados não originários do trabalho - aluguéis, aplicações financeiras, lucros e dividendos - e o patrimônio (SALVADOR, 2016, p. 8).

Ainda de acordo com o referido autor, com base em dados divulgados pela Receita Federal do Brasil, do total de R\$ 5,8 trilhões de bens e direitos declarados ao Fisco em 2013, 41,56\% eram de propriedade de apenas 726.725 pessoas. Indivíduos com rendimentos acima de 40 salários mínimos, o que revela uma brutal concentração de riqueza em apenas o,36\% da população brasileira (SALVADOR, 2016, p. 23).

Um dos fatores que contribuem para essa concentração é justamente o fato das isenções do IR beneficiarem em maior medida os mais ricos. Com base nas declarações apresentadas à Receita no período de 2007 a 2013, Salvador observa que quanto mais elevada é a renda, maior é a proporção dos rendimentos isentos e não tributáveis. Assim, $65,8 \%$ da renda dos 71.440 hiper-ricos, com rendas acima de 160 salários mínimos em 2013, tinha origem em rendimentos isentos e não tributáveis, enquanto 90,26\% da renda dos declarantes da faixa de 2 a 3 salários mínimos provinha de rendimentos tributáveis (SALVADOR, 2016, p. 30).

Outro problema é a crescente perda da progressividade do imposto de renda.

Além da redução da quantidade de faixas e alíquotas observada ao longo dos anos (no período de 1983 a 1985, o IRPF chegou a ter treze faixas de renda e alíquotas, variando de o\% a 6o\%), para isso também contribuem as isenções que favorecem os mais ricos (SALVADOR, 2016, p. 34).

Em razão de todos esses aspectos, a alíquota média efetiva do imposto de renda, calculada a partir do imposto devido em relação aos rendimentos tributáveis somados aos isentos e não tributáveis, tende a diminuir para os contribuintes que se enquadram nas faixas superiores de rendimentos. Ao analisar os dados referentes às declarações do IR de 2013, Salvador chega às seguintes conclusões quanto a alíquota efetiva do tributo:

A partir da faixa de 40 a 80 salários mínimos, o imposto de renda começa a perder sua progressividade. Nesta faixa, a alíquota é rebaixada para 10,09\%; na faixa de 80 a 160 salários mínimos, é reduzida para $6,65 \%$; e, na faixa acima de 160 salários mínimos, a 3,33\%, ou seja, uma alíquota similar à existente na faixa de 5 a 10 salários mínimos. Portanto, os contribuintes com rendimentos acima de 40 salários mínimos passam a pagar proporcionalmente menos IR do que os contribuintes nas faixas salariais inferiores. Em conclusão, quanto maior for a renda recebida pelo contribuinte, menor vai ser a alíquota do IR devido, o que revela uma regressividade do imposto de renda para os contribuintes de maior remuneração (...). As razões dessa situação (...) devem-se ao fato de que os contribuintes de mais alta renda são exatamente aqueles que mais se beneficiam de rendimentos isentos de IR e contam também com tributação exclusiva para parte de suas rendas (...). Esses contribuintes são os principais privilegiados das alterações realizadas nas leis tributárias do país após 1995, destacadamente a isenção do IR sobre lucros e dividendos distribuídos e a criação do mecanismo de juros sobre capital próprio (...) (SALVADOR, 2016, p. 40). 
Especificamente quanto à isenção sobre a distribuição de lucros e dividendos e também com base nos dados divulgados pela Receita, Gobetti e Orair observam que o volume de lucros e dividendos distribuídos no país passou de R\$149 bilhões em 2007 para $\mathrm{R} \$ 287$ bilhões em 2013, beneficiando 2,1 milhões de pessoas (7,9\% dos declarantes do IR). Tais contribuintes têm

[...] maior presença nos estratos do topo, onde chegam a representar $72 \%$ dos declarantes de rendimentos superiores a $\mathrm{R} \$ 1,3$ milhão. Outro dado interessante é que a parcela majoritária dos seus rendimentos é isenta (em média dois terços do total), principalmente nas faixas mais elevadas. Ou seja, existem assimetrias na distribuição dos recebedores de lucros e dividendos, que estão mais concentrados no topo, e a maior parte de sua renda está isenta de imposto (GOBETTI; ORAIR, 2016, p. 17-18).

Diante de tais aspectos da tributação e da desigualdade no Brasil, parece claro que isentar do imposto de renda os rendimentos oriundos da distribuição de lucros e dividendos configura uma inversão da lógica da capacidade contributiva, ao se conferir tratamento privilegiado àqueles que, em regra, detêm uma maior capacidade econômica. Não se trata, portanto, de um fator de discrímen ou medida de comparação que visa lograr uma distribuição mais justa e equânime da carga tributária. Pelo contrário, tal medida tende a agravar a concentração de renda e a desigualdade, sendo ofensiva ao princípio constitucional da isonomia, à luz da progressividade do imposto de renda e da capacidade contributiva aplicável aos impostos em geral (art. 145, § 1ํㅡ, e art. 153, § 2º, I, da CF/88).

Por fim, não cabe objetar que, apesar das razões acima, a tributação sobre os lucros distribuídos estaria de todo modo vedada, sob pena de configuração de bis in idem, que ocorre quando a mesma pessoa jurídica pretende efetivar uma dupla incidência tributária sobre o mesmo fato gerador. Por esse argumento, como os lucros já teriam sido tributados na pessoa jurídica, não poderiam ser objeto de nova incidência do imposto quando de sua distribuição aos sócios. O raciocínio é improcedente. Tratam-se de fatos econômicos diversos: "um consiste no recebimento de lucros, decorrentes de investimentos no capital da pessoa jurídica pela pessoa física, portanto renda desta”; já o outro se trata da "produção de lucros pela pessoa jurídica, decorrentes de suas atividades produtivas, portanto renda da pessoa jurídica”, razão pela qual o mesmo ente político "tem competência para tributar dois fatos geradores distintos, em sua materialidade e temporalidade, por um mesmo tributo" (FERRARESI, 2010, p. 115). Por outro lado, como existem outros valores albergados na Constituição, resta saber se a isenção legal em exame se sustenta com base em alguma outra finalidade extrafiscal de natureza constitucional, à luz de um juízo de proporcionalidade.

\section{A ISENÇÃO SOBRE LUCROS E DIVIDENDOS E A PROMOÇÃO DE OUTRAS FINALIDADES CONSTITUCIONAIS}

Na exposição de motivos do projeto de lei que deu origem à Lei no 9.249/95, o então Ministro da Fazenda apontou as seguintes razões para a pretendida isenção incidente sobre os lucros e dividendos distribuídos pela pessoa jurídica: 
12. Com relação à tributação dos lucros e dividendos, estabelece-se a completa integração entre a pessoa física e a pessoa jurídica, tributandose esses rendimentos exclusivamente na empresa e isentando-os quando do recebimentos pelos beneficiários. Além de simplificar os controles e inibir a evasão, esse procedimento estimula, em razão da equiparação de tratamento e das alíquotas aplicáveis, o investimento nas atividades produtivas (BRASIL, 1995).

Assim, a par da simplificação tributária, o objetivo principal declarado era o de incentivar "o investimento nas atividades produtivas". Tendo em vista que a referida isenção apresenta manifesta contrariedade com as normas constitucionais atinentes à capacidade contributiva e à progressividade, cumpre analisar, neste momento, se a finalidade declarada possui fundamento em algum outro princípio de estatura constitucional. É de ver-se que a falta de controle da finalidade extrafiscal declarada torna bastante vulnerável a efetivação da igualdade, pois é sua indicação precisa que permite aferir a validade da medida de comparação eleita pelo legislador e a consequente diferenciação entre os contribuintes (ÁVILA, 2015, 76).

Oart. $3^{\circ}$, II, da Constituição Federal, consagra como um dos objetivos fundamentais da República Federativa do Brasil "garantir o desenvolvimento nacional”. De seu turno, constitui um dos princípios constitucionais da ordem econômica a "busca do pleno emprego" (art. 170, VIII, da CF/88). Certamente, a pretendida finalidade de incentivar o "investimento nas atividades produtivas" pode ser considerada compatível com a promoção do desenvolvimento nacional e a busca do pleno emprego. Entretanto, até aí se trata de uma compatibilidade estritamente formal. Deve-se questionar se, efetivamente, há razões para sustentar que a aludida isenção contribui para a finalidade perseguida. Nesse passo, por vezes será necessário colher alguns subsídios da área de Economia, sendo insuficiente uma análise exclusivamente jurídica da matéria. Não obstante, o foco principal do estudo permanece sendo o exame da compatibilidade da isenção legal em destaque com o sistema constitucional em vigor.

Em primeiro lugar, registre-se que o Projeto de Lei no 913/1995 aparentemente não se fez acompanhar de nenhum estudo ou avaliação de impacto que permitisse apontar, com base em dados empíricos, a efetiva probabilidade dos efeitos esperados da medida. Em outras palavras, não se identifica, na tramitação do projeto de lei, qualquer referência a dados concretos que permitissem inferir uma relação de causa e efeito entre a isenção do IR sobre a distribuição de lucros e dividendos e o alegado estímulo ao "investimento nas atividades produtivas".

Ao que parece, a referida medida teve por substrato a teoria econômica do "gotejamento" ou trickle down. De acordo com esse pensamento, em linhas gerais, benefícios concedidos a indivíduos ou empresas que se encontram no topo da pirâmide social tendem a gerar efeitos benéficos para toda a sociedade, com a ampliação de investimentos, do consumo e da oferta de empregos. Essa teoria vem sendo severamente questionada por diversos economistas. Ao tratar da realidade dos Estados Unidos da América, país que, a partir do governo Reagan, vivenciou uma série de medidas de redução de tributos para os mais ricos (que influenciaram o mundo todo, inclusive o 
Brasil), com o mesmo objetivo de promover o desenvolvimento nacional, o prêmio Nobel de Economia Joseph Stiglitz afirma o seguinte:

Lembre-se: as taxas baixas de impostos para os ricos deveriam estimular a poupança e o trabalho árduo e, consequentemente, o crescimento econômico. Não fizeram nada disso. Na verdade, a taxa de poupança das famílias caiu a um nível inédito, próximo de zero, depois dos dois cortes sancionados pelo presidente George W. Bush em 2001 e 2003, relacionados aos impostos sobre dividendos e ganhos de capital. O efeito das taxas baixas no topo foi o aumento da rentabilidade sobre a caça à renda, que prosperou, ou seja, o crescimento ficou mais lento e a desigualdade aumentou. Agora este padrão é observado em vários países. Ignorando as advertências daqueles que querem manter seus privilégios, os países que aumentaram a faixa de tributação mais elevada não tiveram crescimento mais lento (STIGLITZ, 2016, p. 179).

Também Atkinson sustenta posição similar, com foco principal na realidade da Grã-Bretanha que, a exemplo dos Estados Unidos, também teve sua experiência de drástica redução de impostos para os mais ricos, especialmente no Governo Thatcher, durante os anos 80 do século passado. Afirma esse autor:

Se uma redução nos impostos fizer com que o $1 \%$ do topo aumente sua renda através de um maior esforço empreendedor, e isso gerar emprego para outros, o efeito da receita deverá incluir também os impostos coletados sobre esses novos funcionários. Isso justificaria uma alíquota tributária inferior. Parece-me, no entanto, que a interdependência provavelmente estará na direção oposta: o aumento da renda do $1 \%$ do topo resultante da redução tributária acontece à custa dos outros contribuintes. Em termos de atividade empreendedora, eles podem estar pescando no mesmo lago, e o aumento da renda do topo reduz as oportunidades para os outros. Um exemplo específico de spillover negativo é fornecido pela remuneração gerencial. No passado, com as altas alíquotas marginais, os executivos de alto cargo viam pouca vantagem em negociar um pagamento maior. Em vez disso, (...) podem ter optado por reinvestir os lucros e assegurar uma expansão mais rápida de suas empresas. A redução nas alíquotas tributárias do topo na década de 1980 fez com que eles mudassem seus esforços no sentido de aumentar remunerações ou bônus, e essa conta acabou sendo paga pelos acionistas (ATKINSON, 2015, p. 228-229).

Do excerto acima, percebe-se que os incentivos resultantes da baixa tributação no topo da pirâmide social podem ter efeito inverso ao pretendido. Assim, ao invés de estimular o investimento em atividades produtivas, a isenção sobre os lucros e dividendos pode gerar incentivos para que uma maior parcela dos lucros auferidos pela pessoa jurídica não sejam reinvestidos na atividade da empresa, mas sim distribuídos entre os sócios. Como afirma Ferraresi, "uma das formas importantes de investimento é a reaplicação dos lucros das empresas em suas atividades produtivas e não a sua distribuição" (FERRARESI, 2010, p. 113).

Nesse mesmo sentidoé a posição de Piketty. Ao comparar o crescimento do PIB dos Estados Unidos e Reino Unido com o de outros países desenvolvidos que não seguiram a mesma política de drástica redução das alíquotas superiores do imposto sobre a renda, aponta não existir nenhuma relação estatisticamente significativa entre a queda da "taxa marginal superior" do imposto e a "taxa de crescimento da produtividade marginal nos 
diferentes países desenvolvidos desde os anos 1970". Segundo esse autor,

[...] o fato é que a taxa de crescimento do PIB por habitante foi quase a mesma em todos os países ricos desde os anos 1970-1980. Ao contrário do que às vezes se imagina no Reino Unido ou nos Estados Unidos, a verdade dos dados - tanto quanto for possível avaliar a partir das contas nacionais - é que o crescimento não foi mais forte desde os anos 1970-1980 nesses países do que na Alemanha, na França, no Japão, na Dinamarca ou na Suécia. Em outras palavras, a redução da taxa marginal superior e o aumento das rendas elevadas não parecem ter estimulado a produtividade (ao contrário das previsões da teoria da oferta), ou pelo menos não o bastante para que isso seja estatisticamente perceptível no contexto econômico como um todo (PIKETTY, 2014, p. 496-497).

Opróprio FMI, instituiçãoidentificada compolíticas radicaisdeajustefiscal,típicas do que se costuma denominar de neoliberalismo econômico, tem divulgado estudos que demonstram uma crescente preocupação com a desigualdade, como um fator que pode prejudicar o desenvolvimento econômico. De acordo com uma das conclusões de recente estudo, haveria uma relação inversamente proporcional entre uma maior concentração de renda para os $20 \%$ mais ricos e o crescimento econômico, sugerindo que os benefícios concedidos ao topo não "gotejam" (trickle down) para beneficiar a sociedade em geral. Além disso, a desigualdade de renda afeta o ritmo pelo qual o crescimento contribui para a redução da pobreza. O crescimento é menos eficiente em reduzir a pobreza nos países com altos índices de desigualdade. E dentre as medidas que o mesmo estudo recomenda para o combate à desigualdade também se encontra a maior progressividade dos sistemas tributários. Os autores do estudo apontam que a restrição de medidas que beneficiam os grupos de alta renda, como a taxação reduzida de ganhos de capital, pode diminuir a desigualdade e permitir um corte na tributação incidente sobre as rendas do trabalho, a fim de estimular o crescimento (DABLA-NORRIS et al, 2015, p. 7, 9, 30).

De acordo com os estudos acima referidos, portanto, a redução de impostos para os mais ricos, além da injustiça que lheé inerente, por ofensiva à igualdade e à capacidade econômica dos contribuintes, também não contribui decisivamente para o crescimento, podendo até mesmo produzir efeitos que lhe sejam danosos.

Em análise específica da realidade brasileira e dos efeitos esperados quanto à isenção da distribuição de lucros e dividendos, afirmam Gobetti e Orair que

[...] a literatura empírica carece de resultados conclusivos que demonstrem que os benefícios tributários aos rendimentos da propriedade do capital (...) obtiveram êxito em ampliar os investimentos no país, já que, ao contrário, os investimentos permaneceram estagnados por mais de uma década após a implementação dessas medidas. Por outro lado, o que se pode afirmar de maneira inequívoca é que consolidaram o quadro de subtributação do lucro no país e contribuíram para a baixa progressividade do IRPF (...) (GOBETTI; ORAIR, 2016, p. 14-15).

Finalmente, ao analisar os efeitos da isenção legal instituída no Brasil, a Consultoria Legislativa da Câmara dos Deputados também concluiu, em recente parecer, que ambos os efeitos esperados (simplificação fiscal com combate à evasão e estímulo ao investimento produtivo) foram frustrados, pelas seguintes razões: 


\begin{abstract}
A combinação da isenção com o regime de lucros fictos do lucro presumido e do SIMPLES acabou por frustrar ambos os objetivos. O controle fiscal foi dificultado, pois a pessoa jurídica não mais recolheria IRPJ sobre a totalidade de sua receita, ficando restrita à presunção legal. A cominação também importou na concessão de benefício fiscal pouco transparente, bem como na tendência à reorganização dos negócios de profissionais liberais como pessoas jurídicas ("pejotização"). Essa tendência implica tratamento desigual entre trabalhadores assalariados e profissionais liberais, pois valores que, na realidade, têm natureza de honorários são tratados como lucros, fugindo à tributação (QUEIROZ E SILVA, 2015, p. 45).
\end{abstract}

Assim, não se verifica a existência de dados que atestem a ocorrência dos efeitos esperados quando da edição da lei que instituiu a isenção do imposto de renda sobre a distribuição de lucros e dividendos da pessoa jurídica. Os estudos analisados, ao contrário, apontam justamente para a ineficácia de medidas dessa natureza.

\title{
5. A INCONSTITUCIONALIDADE DA ISENÇÃO SOBRE LUCROS E DIVIDENDOS EM FACE DO POSTULADO DA PROPORCIONALIDADE
}

Neste tópico, cumpre recordar algumas concepções sobre princípios e a forma de se resolver eventuais conflitos entre princípios contrapostos. Inicialmente, dentre os autores que tratam do tema, vale destacar a contribuição de Dworkin, para quem princípios configuram um padrão a ser observado por ser uma exigência de justiça ou equidade ou de alguma outra dimensão da moralidade. Seriam distintos do que chama de policies, as quais estabelecem metas a serem alcançadas para promover melhorias em algum aspecto econômico, político ou social da comunidade. Os princípios (assim como as policies) possuem uma dimensão de peso. Quando se cruzam, o conflito deve ser resolvido levando em conta o peso relativo de cada um. Isso não possibilita uma medição exata, de modo que a conclusão sobre a maior importância de determinado princípio sobre outro sempre será controvertida. Trata-se de consequência inevitável dessa dimensão de peso própria dos princípios (DWORKIN, 1978, p. 22, 26-27).

Em busca de uma maior precisão sobreo conceito de princípios ea forma de resolução de conflitos entre eles, Alexy define princípios como mandamentos de otimização, normas que ordenam a realização de algo "na maior medida possível, dentro das possibilidades jurídicas e fáticas existentes", podendo ser satisfeitos em graus variados, sendo que o âmbito das possibilidades jurídicas da medida de sua satisfação é determinado pelos princípios e regras colidentes. Se há colisão entre dois princípios, quando algo é proibido de acordo com um princípio e permitido de acordo com outro, um deles terá de ceder, sem que seja declarado inválido. Um dos princípios terá precedênciaem relação aooutro sobdeterminadas condições; sob outras condições, a precedência pode pender para o lado oposto. Para o sopesamento dos princípios em jogo em determinada situação, o postulado ou máxima da proporcionalidade possui importância fundamental. A própria natureza dos princípios como mandamentos de otimização implica a máxima da proporcionalidade, com suas três máximas parciais da adequação, necessidade e proporcionalidade em sentido estrito. A necessidade e a adequação tratam das possibilidades fáticas da ponderação, enquanto a proporcionalidade em sentido 
estrito se refere às possibilidades jurídicas (ALEXY, 2011, p. 90, 93-94, 116-118).

O postulado (ou máxima) da proporcionalidade demanda que o Legislativo e o Executivo optem, para a realização dos fins pretendidos, por meios adequados, necessários e proporcionais. Adequado é aquele que se revela idôneo, eficaz, para promover o fim pretendido. Será necessário se, dentre os meios adequados existentes, for o menos restritivo em relação a outros valores igualmente protegidos pelo ordenamento. Finalmente, o meio deve ser proporcional em sentido estrito, vale dizer, os benefícios que promove em relação ao fim buscado devem ser superiores aos prejuízos que acarrete aos valores contrapostos a esse fim (ÁVILA, 2006, p. 146).

Assim, em determinada situação concreta, conflitos entre princípios de igual estatura constitucional devem ser resolvidos com base em razões de proporcionalidade. O sacrifício pontual de determinado princípio à luz dos interesses em jogo somente pode ser admitido se tratar-se de medida adequada, necessária e proporcional em sentido estrito para a finalidade de garantia da eficácia do princípio contraposto.

Especificamente no tocante à igualdade tributária, calcada na capacidade econômica dos contribuintes, deve-se atentar para a eventual finalidade extrafiscal da medida tendentea relativizarotratamentoigualitárioconformeacapacidadecontributiva. Nessa situação, a medida de comparação não será a capacidade contributiva, mas outro elemento ou propriedade que tenha relação de pertinência com a finalidade eleita, sujeitando-se ao controle de proporcionalidade. Dessa forma, para afastar a presunção de igualdade com base na capacidade contributiva, não é suficiente apenas justificar; é necessário demonstrar que a medida de distanciamento da igualdade contribui para a realização da finalidade extrafiscal (adequação), é a menos restritiva dentre as que poderiam ser utilizadas para o alcance do mesmo fim (necessidade) e os efeitos positivos decorrentes da promoção da finalidade extrafiscal não são desproporcionais aos efeitos negativos decorrentes do afastamento pontual da igualdade (ÂVILA, 2015, p. 166-168).

À luz dos estudos apresentados no tópico anterior, a isenção em exame teria se revelado inadequada para a eficaz promoção da finalidade extrafiscal buscada pelo legislador, não atendendo ao primeiro requisito da máxima da proporcionalidade.

Se a medida é inadequada para a promoção dos fins pretendidos, já poderia ser qualificada como desproporcional, pois a proporcionalidade pressupõe a verificação cumulativa de seus trêsaspectos (adequação, necessidade eproporcionalidadeem sentido estrito). Seria despiciendo, assim, tecer considerações sobre o fato de ser a menos gravosa em relação a outras igualmente eficazes para a promoção dos fins (necessidade) ou sobre a proporcionalidade dos efeitos positivos obtidos em relação aos efeitos negativos de restrição da igualdade (proporcionalidade em sentido estrito).

Nesse passo, pode-se contrapor o argumento de que uma análise retrospectiva, com base em dados verificados após cerca de vinte anos desde a edição da lei, não seria idônea para autorizar a conclusão de que o legislador teria faltado com o dever de proporcionalidade, de modoajustificaruma eventual declaraçãodeinconstitucionalidade por ofensa ao princípio da isonomia. A adequação deve ser avaliada no momento da decisão tomada pelo Poder Público e não posteriormente, pois a conclusão acerca da 
qualidade da opção escolhida deve levar em conta as circunstâncias presentes na época da escolha (ÁVILA, 2006, p. 155-156). Pode-se argumentar, assim, que à época da edição da lei, prevalecia certo consenso (inclusive na esfera internacional) de que a concessão do referido favor fiscal poderia servir de estímulo à economia. De modo que aparentava se tratar de medida efetivamente adequada para promover a finalidade extrafiscal então perseguida. A par disso, também seria possível sustentar que, à luz das circunstâncias, tratava-se da medida menos onerosa disponível, por não tornar mais gravosa a situação de nenhum contribuinte, na medida em que apenas instituía um regime fiscal privilegiado para aqueles que teriam condições de, em última instância, promover o desenvolvimento e o bem-estar geral. Finalmente, seria proporcional em sentido estrito, pois os benefícios esperados na ocasião compensariam os prejuízos à igualdade, mormente em se considerando o referido aspecto de que a isenção não tornaria pior o regime fiscal já incidente para os demais contribuintes.

É fato que não se pode ignorar os riscos de se recorrer de forma excessiva à ponderação de princípios. O eventual abuso na ponderação pode resultar em uma indesejável insegurança jurídica, com grave ofensa aos princípios da separação dos Poderes e da legalidade, autorizando-se a prevalência de interesses os mais diversos ao sabor das mudanças de entendimento do Judiciário, sob ovéu pretensamente legitimador de um isento e técnico juízo de proporcionalidade.

Em crítica ao uso abusivo da ponderação, Neves alerta para o risco de se desenvolver uma ponderação ad hoc, dependente dos interesses concretos envolvidos em cada caso, "sob o manto retórico dos princípios". De modo que essa invocação retórica dos princípios para a solução de todos os problemas constitucionais, seja pela absolutização de princípios ou por uma ponderação compulsiva, além de simplificadora, pode encobrir práticas orientadas à satisfação de interesses avessos à constitucionalidade e levar à erosão da força normativa da Constituição (NEVES, 2014, p. 196).

Deve-se preservar um mínimo de liberdade para o legislador escolher os meios destinados ao alcance das diversas finalidades impostas constitucionalmente. Os princípios da separação dos Poderes e da legalidade assim impõem. De modo que a inadequação da medida eleita, conforme as circunstâncias do momento de sua adoção, deve estar cabalmente evidenciada para autorizar sua invalidação pelo Judiciário. De acordo com Ávila, o âmbito de controle da proporcionalidade de determinada lei pelo Judiciário será tanto menor quanto mais duvidoso for seu efeito futuro, "difícil e técnico for o juízo exigido para o tratamento da matéria" e "aberta for a prerrogativa de ponderação" atribuída ao Legislativo pela Constituição (2006, p. 162).

Todos esses pontos são pertinentes, porém não se pode perder de vista o ônus do legislador em demonstrar a legitimidade da opção discriminatória realizada, especialmente quando utiliza critério distintivo preliminarmente vedado ou não adota aquele imposto como regra geral pela Constituição. Em tais situações, o tratamento desigual exige ainda maiores razões para ser considerado como válido. Ao tornar obrigatório o critério da capacidade contributiva para os impostos, o constituinte determinou que os contribuintes devem ser tratados em conformidade com sua 
capacidade contributiva pessoal, salvo em existindo razões extremas para a eleição de outro critério de tratamento (ÁVILA, 2015, p. 160-162).

Assim, se a Constituição prescreve expressamente que, sempre que possível, os impostos devem ser graduados de acordo com a capacidade econômica dos contribuintes (art. 145, § $1^{\text {o}}$ ) e que o imposto de renda deve observar o critério da progressividade (art. 153, § 2º- I), supõe-se que tais determinações devam ter um mínimo de eficácia. Tais regras tornam mais restritiva e fechada a prerrogativa de ponderação atribuída ao Legislativo. Ao instituir uma isenção que beneficia os contribuintes dotados de maior capacidade econômica e aprofunda a regressividade do sistema tributário nacional, o legislador deixa de adotar a medida de comparação expressamente eleita pela Constituição. Para assim proceder de forma legítima, não basta simplesmente invocar alguma finalidade extrafiscal passível de ser reconduzida a outro princípio constitucional. Se assim fosse, seria muito fácil esvaziar o conteúdo da igualdade tributária ou de qualquer princípio ou direito fundamental. A liberdade do legislador não pode ser plena e ilimitada a esse ponto, sob pena de também restar configurado grave risco de erosão da força normativa da Constituição.

Na situação em exame, o ente estatal não se desincumbiu a contento do ônus argumentativo e comprobatório necessário à instituição do tratamento desigual em questão. Mesmo à época da edição da lei não se verifica o mínimo de comprovação quanto ao esperado estímulo ao "investimento nas atividades produtivas" que seria decorrente da medida. É insuficiente a mera menção do então Ministro da Fazenda acerca da finalidade pretendida, sem fazer referência a qualquer dado ou avaliação de impacto que sustentasse a crença na eficácia da medida.

Assim, a produção de estudos recentes, que apontam para sua ineficácia e recomendam medidas em sentido contrário, a rigor não são decisivos para se concluir pela inadequação e desproporcionalidade da isenção em exame. Tal conclusão decorre, essencialmente, da falta de justificação e demonstração suficiente na época mesmo da elaboração da lei, especialmente necessária em face da adoção de medida de comparação contrária à determinação constitucional expressa. As avaliações e estudos posteriores apenas confirmam e reforçam o vício que já se encontrava presente na regra legal desde o início. Por outro lado, caso avaliações posteriores demonstrassem a eficácia da medida, embora editada sem as devidas cautelas, não haveria razão para se concluir por sua invalidade, sob pena de excesso de formalismo e desrespeito ao espaço legítimo de liberdade do Legislativo.

Portanto, em face de todas as razões até aqui expostas, a isenção da distribuição de lucros e dividendos relativa ao imposto sobre a renda, instituída por meio do art. 10 da Lei no 9.249/95, ofende o princípio constitucional da igualdade, por não observar os critérios da capacidade contributiva e da progressividade, aplicáveis ao imposto de renda por determinações constitucionais expressas. Também não se justifica à luz da finalidade extrafiscal de promover o "investimento nas atividades produtivas", caracterizandose como medida inadequada e, consequentemente, desproporcional para o alcance da finalidade declarada. Passível, portanto, de declaração de inconstitucionalidade 
pelo Poder Judiciário, sem que isso configure o risco real de abuso na ponderação de princípios, o qual não se encontra presente na situação ora examinada.

De todo modo, nada impede que o próprio Legislativo promova a revogação da referida isenção, o que evitaria questionamentos sobre eventuais excessos do Judiciário. Nesse passo, é de ver-se que existem projetos de lei em tramitação que visam revogar a isenção em análise, utilizando-se de argumentos similares aos expostos no presente estudo. ${ }^{4}$

\section{CONCLUSÃO}

À guisa de conclusão, cumpre traçar apenas algumas considerações finais sobre o tema em análise. Inicialmente, os dados expostos permitem vislumbrar que o sistema tributário brasileiro promove a regressividade e a concentração de renda no país, o que vai de encontro a dispositivos constitucionais expressos que consagram a isonomia na tributação, especialmente a capacidade contributiva e a progressividade para o imposto de renda. O que prevalece, portanto, é uma situação de inegável injustiça fiscal, que tende a privilegiar justamente aqueles dotados de maior capacidade econômica, em ofensa direta à capacidade contributiva, a qual, "sempre que possível”, deve ser aplicada na graduação dos impostos, conforme a expressa dicção do texto constitucional (art. 145, $\left.\S 1^{\mathrm{o}}\right)$.

A isenção sobre lucros e dividendos de que trata o art. 10 da Lei no 9.249/95 apenas agrava essa situação, pois incide sobre rendimentos percebidos, em sua grande maioria, pela parcela mais rica da sociedade. Dessa forma, sua instituição se justificaria apenas se calcada em alguma finalidade extrafiscal passível de recondução a algum princípio de estatura constitucional, desde que preenchidos os requisitos de proporcionalidade para o sacrifício pontual da isonomia (adequação, necessidade e proporcionalidade em sentido estrito). Requisitos que demandam, na situação em exame, um ônus especialmente elevado de demonstração, em face da prevalência abstrata da capacidade contributiva e progressividade como critérios que devem, em regra, ser observados na tributação sobre a renda.

Nesse passo, além de ter o condão de agravar a situação de desigualdade na tributação, não há elementos queapontem para a real eficácia da medida em promovero desenvolvimento econômico, por meio de pretensos estímulos a investimentos produtivos. Sequer no encaminhamento do projeto de lei que deu origem à isenção se verifica algum estudo ou avaliação de impacto que sustentasse essa crença. Tudo isso revela a desproporcionalidade e consequente inconstitucionalidade da medida por afronta à isonomia, a qual pode ser validamente declarada pelo Judiciário, sem que se possa falar em ofensa aos princípios da legalidade e separação de Poderes, decorrente de um eventual abuso na ponderação de princípios. Não obstante, a melhor opção seria mesmo a revogação da isenção pelo próprio Legislativo, a fim de evitar questionamentos desse tipo, sendo certo que existem projetos de lei em tramitação com esse objetivo.

4 No Senado Federal, existem ao menos três projetos de lei que visam restaurar a tributação sobre a renda decorrente da distribuição de lucros (PLS no 588/15, PLS no 616/15 e PLS no 639/15). 


\section{REFERÊNCIAS}

ALEXY, Robert. Teoria dos direitos fundamentais. São Paulo: Malheiros, 2011.

ATKINSON, Anthony B. Desigualdade: o que pode ser feito? São Paulo: Leya, 2015.

ÁVILA, Humberto. Teoria da igualdade tributária. São Paulo: Malheiros, 2015.

Teoria dos princípios. São Paulo: Malheiros, 2006.

BANDEIRA DE MELLO, Celso Antônio. Conteúdo jurídico do princípio da igualdade. São Paulo: Malheiros, 2003.

BRASIL. Congresso. Câmara dos Deputados. Projeto de Lei no 913/95. Altera a legislação do imposto de renda das pessoas jurídicas e dá outras providências. Disponível em: < http://www.camara.gov.br/proposicoesWeb/fichadetramitacao?idProposicao $=184392$ >. Acesso em: 25 jan. 2017.

BRASIL. Constituição da República Federativa do Brasil, 1988. Disponível em: < http://www.planalto.gov.br/ccivil_03/constituicao/constituicaocompilado.htm >. Acesso em: 31 jan. 2017.

BRASIL. Lei no 9.249, de 26 de dezembro de 1995. Altera a legislação do imposto de renda das pessoas jurídicas, bem como da contribuição social sobre o lucro líquido, e dá outras providências. Disponível em: < http://www.planalto.gov.br/ccivil_03/leis/L9249. htm >. Acesso em: 31 jan. 2017.

DABLA-NORRIS, Era et al. Causes and consequences of income inequality: a global perspective. International Monetary Fund. Strategy, Policy and Review Department. June 2015. Disponível em: < https://www.imf.org/external/pubs/ft/sdn/2015/sdn1513. pdf $>$. Acesso em: 31 jan. 2017.

DWORKIN, Ronald. Taking Rights Seriously. Cambridge: Harvard University Press, 1978.

FERRARESI, Luiz Carlos. Isenção de imposto de renda para lucros distribuídos. In: Revista Linhas Jurídicas (UNIFEV), v. 1, n. 2, p. 112-119, nov. 2010.

GOBETTI, Sérgio Wulff e ORAIR, Rodrigo Octávio. Progressividade tributária: a agenda negligenciada. Texto para discussão/Instituto de Pesquisa Econômica Aplicada. Brasília, Rio de Janeiro: 2016. Disponível em: < http://repositorio.ipea.gov.br/ bitstream/11058/6633/1/td_219o.pdf >. Acesso em: 31 jan. 2017. 
KELSEN, Hans. Teoria Pura do Direito. São Paulo: Martins Fontes, 1999.

MÉLO, Luciana Grassano de Gouvêa. Estado social e tributação: uma abordagem sobre o dever de informar e a responsabilidade por infração. Recife: Ed. Universitária da UFPE, 2008.

NEVES, Marcelo. Entre Hidra e Hércules: princípios e regras constitucionais como diferença paradoxal do sistema jurídico. São Paulo: WMF Martins Fontes, 2014.

PIKETTY, Thomas. O capital no século XXI. Rio de Janeiro: Intrínseca, 2014. QUEIROZ E SILVA (coord). Tributação de lucros e dividendos no Brasil: uma perspectiva comparada. Câmara dos Deputados. Consultoria Legislativa. Brasília: Novembro/2015. Disponível em: < http://www2.camara.leg.br/documentos-e-pesquisa/ publicacoes/estnottec/areas-da-conle/tema2o/2015_19898-tributacao-de-lucros-edividendos-jules-michelet-et-all >. Acesso em: 31 jan. 2017.

SALDANHA SANCHES, J. L. Justiça Fiscal. Lisboa: Fundação Francisco Manuel dos Santos, 2010.

SALVADOR, Evilásio. Perfil da desigualdade e da injustiça tributária com base nos declarantes do imposto de renda no Brasil 2007-2013. Instituto de Estudos Sócioeconômicos - INESC. Brasília: 2016. Disponível em: < https://www.oxfam.org.br/ publicacoes/perfil-da-desigualdade-e-da-injustica-tributaria >. Acesso em: 31 jan. 2017.

SCHOUERI, Luís Eduardo. Normas tributárias indutoras e intervenção econômica. Rio de Janeiro: Forense, 2005.

STIGLITZ, Joseph E.. O grande abismo. Sociedades desiguais e o que podemos fazer sobre isso. Rio de Janeiro: Alta Books, 2016.

VASQUES, Sérgio. O Princípio da Equivalência como Critério de Igualdade Tributária. Coimbra: Almedina, 2008. 